\title{
Establishment of a patient-derived mucoepidermoid carcinoma cell line with the CRTC1-MAML2 fusion gene
}

\author{
KAZUMA NOGUCHI $^{1 *}$, SHUJI KANDA ${ }^{1 *}$, KAZUNARI YOSHIDA $^{1}$, YUSUKE FUNAOKA $^{1}$, KOJI YAMANEGI $^{2}$, \\ KYOHEI YOSHIKAWA ${ }^{1}$, KAZUKI TAKAOKA ${ }^{1}$, HIROMITSU KISHIMOTO ${ }^{1}$ and YOSHIRO NAKANO ${ }^{3}$ \\ Departments of ${ }^{1}$ Oral and Maxillofacial Surgery, ${ }^{2}$ Pathology and ${ }^{3}$ Genetics, \\ Hyogo College of Medicine, Nishinomiya, Hyogo 663-8501, Japan
}

Received November 29, 2019; Accepted October 8, 2021

DOI: $10.3892 / \mathrm{mco} .2022 .2508$

\begin{abstract}
Mucoepidermoid carcinoma (MEC) is the most common malignant tumor of the major and minor salivary glands. Surgical resection is the only curative treatment and there is no effective post-operative therapy for MEC. The present study reports an Institutional Review Board-approved case of a 45-year-old Japanese female diagnosed with low-grade MEC in the hard palate. Radical resection, supraomohyoid neck dissection and antero-lateral thigh flap reconstruction was performed. A MEC cell line was then established from the resected tumor tissue. Short tandem repeat profiling confirmed the origin and authenticity of the cell line, that harbors a CRTC1-MAML2 translocation, which is frequently observed in MEC. Amphiregulin (AREG), identified as one of the targets of the CRTC1-MAML2 fusion gene, was expressed in the cell line. The AREG receptor, epidermal growth factor receptor (EGFR) was also highly phosphorylated. The results predicted that AREG-EGFR signaling, which is required for tumor growth and survival, might be activated in the cell line in a cell-autonomous manner. As AREG expression is associated with EGFR-targeted drug resistance, this cell line might assist with the identification of novel strategies for MEC treatment.
\end{abstract}

\section{Introduction}

Mucoepidermoid carcinoma (MEC), representing 5\% of all salivary gland tumors and $26 \%$ of malignant salivary gland

Correspondence to: Dr Kazuma Noguchi, Department of Oral and Maxillofacial Surgery, Hyogo College of Medicine, 1-1 Mukogawa-cho, Nishinomiya, Hyogo 663-8501, Japan

E-mail: knoguchi@hyo-med.ac.jp

*Contributed equally

Abbreviations: MEC, mucoepidermoid carcinoma; AREG, amphiregulin; EGFR, epidermal growth factor receptor

Key words: patient-derived cell line, mucoepidermoid carcinoma, salivary gland carcinomas, CRTC1-MAML2, fusion gene tumors registered for the last 39 years in Hiroshima, Japan, is the most common malignant tumor of the major and minor salivary glands $(1,2)$. MEC is characterized by its cellular heterogeneity and consists of mucin-producing, epidermoid and intermediate cells. Clinical and pathological parameters (age, tumor size, presence of cervical lymphadenopathy, distant spread, perineural invasion and histological grade) of MEC have been associated with tumor biological behavior and patient management (3). Pathological classification of MEC is graded as low-, intermediate- or high-grade based on adverse features, such as perineural invasion, angiolymphatic invasion, coagulative necrosis, infiltrative growth, high mitotic rate, anaplasia and cystic components of $<20 \%$ (4).

An important genetic abnormality in MEC is the translocation between chromosomes 11q and 19p, which has been hypothesized to be an early event in the pathogenesis of MEC $(5,6)$, and has been reported in $>50 \%$ of MEC tumors (7). Low-grade tumors have a higher incidence rate of this fusion compared with that in high-grade tumors (8) and patients with fusion-positive cancer tend to have improved survival time, with significantly lower risks of recurrence, metastases or cancer-related mortality (9). The majority of fusion genes in MEC are associated with a specific chromosomal $t(11 ; 19)$ (q14-21;p12-13) translocation that joins exon 1 of the cAMP response element-binding (CREB) protein-binding domain of CREB-regulated transcription coactivator 1 (CRTC1) gene to exons 2-5 of the Notch coactivator mastermind-like gene 2 (MAML2) gene, resulting in the expression of a new CRTC1-MAML2 fusion gene (10). This translocation generates a fusion protein comprised of CRTC1 (also called MECT1, TORC1 or WAMP1) at 19q21 and the C-terminal transcriptional activation domain of MAML2 at 11q21 (11-14). Previous analysis suggested that another member of the CRTC family, at 15q26, CRTC3, also fused with MAML2 (15). Okabe et al (16) and Nakayama et al (17) showed that CRTC1-MAML2 or CRTC3-MAML2 fusions occurred in 40-80\% of primary salivary gland MECs, and was associated with a distinct tumor subset that had favorable clinicopathological features and an indolent clinical course.

Previously, amphiregulin (AREG), a member of the epidermal growth factor (EGF) family, was identified as a target of the CRTC1-MAML2 fusion gene and secreted AREG was shown to activate EGF receptor (EGFR) signaling in an 
autocrine manner (18). Furthermore, mutations in EGFR itself are rare in salivary gland carcinomas (19), while copy number alternations in EGFR are frequently found in high-grade MEC, regardless of fusion gene positivity (20). The molecular pathology and oncology of MEC are still poorly understood. Established authentic cell lines are essential to determine the biological characteristics of MEC, and a number of cell cultures and models have emerged; however, the cell line usability is limited (21). The present study reports the establishment of a MEC cell line (HCM-MEC010) carrying the CRTC1-MAML2 fusion gene and activated EGFR. The potential uses for this cell line will also be discussed to understand the biological characteristics of MEC.

\section{Materials and methods}

Cell line generation and cell culture. A patient with MEC provided consent in accordance with Hyogo College of Medicine (Hyogo, Japan) institutional policies. Tumor samples were obtained according to an approved Institutional Review Board protocol of Hyogo College of Medicine (approval no. 276; Hyogo, Japan). The present study was also conducted in accordance with the Declaration of Helsinki. Clinical and pathological data were collected from the medical records of the patient. Tumor tissues were minced into 1-2-mm pieces with a disposable scalpel and placed in primary culture. To separate the stromal cells from the mass culture, a magnetic-activated cell sorting (MACS) system was used. Briefly, MACS buffer, containing 1X PBS, 0.5\% BSA, 2 mM EDTA (pH 7.2) (cat. no. 130-042-901; Miltenyi Biotec Inc.), was pre-cooled to $4^{\circ} \mathrm{C}$. To remove the fibroblasts, the single cell suspension was centrifuged at $300 \mathrm{x}$ g for $10 \mathrm{~min}$ at room temperature. and positive selection was performed using CD326 (EpCAM) MicroBeads and a MidiMACSTM Separator (Miltenyi Biotic $\mathrm{GmbH}$ ), according to the manufacturer's instructions. The obtained primary human MEC cells were seeded in F-medium (22) with $10 \mu \mathrm{M}$ Y-27632 (FUJIFILM Wako Pure Chemical Corporation). After 1 week, the culture medium was replaced with fresh medium, which was changed every 4 days thereafter. At the same time, the fibroblasts derived from the tumor tissue of the same patient, were obtained and grown in F-medium. Once cells reached confluence $(80 \%)$, they were washed with PBS ( $\mathrm{Mg}^{2+}$ and $\mathrm{Ca}^{2+}$ free) (23) and detached with $0.05 \%$ EDTA/trypsin for $5 \mathrm{~min}$ at $38^{\circ} \mathrm{C}$ (24). After centrifugation at $167 \mathrm{x} \mathrm{g}$ for $5 \mathrm{~min}$ at $4^{\circ} \mathrm{C}$, the MEC cells were resuspended in F-medium, containing Y-27632 and seeded $\left(0.3 \times 10^{6}\right.$ cells $)$ in $60 \mathrm{~mm}$ dishes. An epithelial cell line was successfully established from the sample of the patient and was termed HCM-MEC010. The morphology of the exponentially proliferating cells in a monolayer was reviewed and documented using inverted phase contrast microscopy. The cells were also tested for mycoplasma infection using the MycoAlert ${ }^{\circledR}$ Assay (Lonza Group, Ltd.) and the cell culture growth medium and with fluorescent microscopy using the Mycoplasma Hoechst Stain Assay (MP Biomedicals, LLC).

Short tandem repeat (STR) authentication of the MEC cell line. To verify the identity of the cell line, genomic DNA was extracted from the blood of the patient, whose tumor sample was used to generate the HCM-MEC010 cell line, as well as from the cell line using the QIAamp DNA Mini kit (Qiagen, Inc.) according to the manufacturer's protocol. DNA genotyping using STR profiling was performed using the GenePrint 10 System (Promega Corporation) and the Applied Biosystems 3130xl Analyzer (Applied Biosystems; Thermo Fisher Scientific, Inc.) and analyzed by BEX Co., Ltd. The evaluation value $(\mathrm{EV})$ was determined using the following equation: $\mathrm{EV}=$ (number of coincidental peaks) $\mathrm{x} 2 /$ total number of peaks in cell $\mathrm{A}$ and total number of peaks in cell $\mathrm{B}$.

Reverse transcription (RT)-PCR of the CRTC1-MAML2 fusion oncogene. The HCM-MEC010 cell line was plated in 100-mm dishes and cultured to $90 \%$ confluence. RNA was extracted using TRIzol ${ }^{\circledR}$ (Invitrogen; Thermo Fisher Scientific, Inc.) and RT-PCR was performed using the PrimeScript RT-PCR kit (Takara Bio, Inc.) according to the manufacturer's instructions. The following primers were used: CRTC1 forward 1, 5'-TTC GAGGAGGTCATGAAGGA-3' and 2, 5'-ATGGCGACT TCGAACAATCCGCGGAA-3'; MAML2 reverse 1, 5'-TTG CTGTTGGCAGGAGATAG-3' and 2, 5'-GGGTCGCTTGCT GTTGGCAGGAG-3' (18), which amplified 101 and 194 bp fragments, respectively. Amplification of the GAPDH gene (forward, 5'-CAATGACCCCTTCATTGACC-3' and reverse, 5'-GACAAGCTTCCCGTTCTCAG-3') was performed as a control. Successfully amplified RT-PCR products of the CRTC1-MAML2 fusion gene were purified and sequenced (24) using BigDye ${ }^{\mathrm{TM}}$ Terminator v3.1 Cycle Sequencing kit (Thermo Fisher Scientific, Inc.) and 2\% agarose gel electrophoresis.

Western blot analysis. The culture medium was removed and the cells were washed with PBS $\left(\mathrm{Mg}^{2+}\right.$ and $\mathrm{Ca}^{2+}$ free). RIPA buffer was added (cat. no. sc-24948; Santa Cruz, Inc.) and the cells were incubated at $4^{\circ} \mathrm{C}$ for $60 \mathrm{~min}$, then centrifuged at $12,000 \mathrm{x} \mathrm{g}$ for $20 \mathrm{~min} 4^{\circ} \mathrm{C}$. The supernatant was the total cell lysate. Proteins were extracted from the HCM-MEC010 and human tongue squamous cell carcinoma (SAS; purchased from the Japanese Collection of Research Bioresources Cell Bank) cell lines as previously described (25). Protein concentration was measured using a Bradford assay (26) Western blot analysis was performed as previously described (25). The primary and secondary antibodies are listed in Table I. The protein expression ratio, compared with that in SAS cells, was measured using ImageJ v1.53e software (National Institutes of Health). The data are presented as the mean \pm SD. The experiment was repeated three times.

Immunofluorescence staining. The cultured HCM-MEC010 and SAS cell lines were fixed in $3.7 \%$ formaldehyde for $20 \mathrm{~min}$ at room temperature. After permeabilization with $0.2 \%$ Triton-X/PBS for $5 \mathrm{~min}$ at room temperature, the cells were blocked with $2 \%(\mathrm{w} / \mathrm{v})$ BSA (Nacalai Tesque, Inc.)/PBS, then washed with PBS $\left(\mathrm{Mg}^{2+}\right.$ and $\mathrm{Ca}^{2+}$ free $)$ and incubated with the primary antibodies overnight at $4^{\circ} \mathrm{C}$. The cells were washed with PBS $\left(\mathrm{Mg}^{2+}\right.$ and $\mathrm{Ca}^{2+}$ free), then incubated with the secondary antibody and Rhodamine phalloidin (Cytoskeleton, Inc.) for $2 \mathrm{~h}$ at room temperature. The samples were mounted in Vecta shield containing DAPI (Vector Laboratories). Fluorescent images were captured using a 
Table I. Primary and secondary antibodies used for western blot analysis and immunofluorescence.

A, Primary antibodies

Dilution

\begin{tabular}{lcccc} 
Name & Cat. no. & Western blot & Immunofluorescence & Supplier \\
\cline { 3 - 4 } Rabbit monoclonal anti-EGFR & 4267 & $1 / 1000$ & $1 / 60$ & CST \\
Rabbit monoclonal anti-p-EGFR & 3777 & $1 / 1000$ & & CST \\
Rabbit monoclonal anti-AKT & 4691 & $1 / 1000$ & & CST \\
Rabbit monoclonal anti-p-AKT & 4060 & $1 / 1000$ & CST \\
Rabbit monoclonal anti-AREG & $16036-1-$ AP & $1 / 1000$ & $1 / 100$ & ProteinTech Group, Inc. \\
Rabbit monoclonal anti-E-cadherin & 3195 & $1 / 1000$ & $1 / 100$ & CST \\
Rabbit monoclonal anti-N-cadherin & 13116 & $1 / 1000$ & $1 / 100$ & CST \\
Rabbit monoclonal anti-vimentin & 5741 & $1 / 1000$ & & CST \\
Rabbit monoclonal anti-tubulin & 2148 & $1 / 1000$ & & CST \\
Mouse monoclonal anti-actin & 47778 & $1 / 1000$ & & \\
\hline
\end{tabular}

B, Secondary antibodies

Dilution

\begin{tabular}{|c|c|c|c|c|}
\hline \multirow[b]{2}{*}{ Name } & \multirow[b]{2}{*}{ Cat. no. } & & \multirow[b]{2}{*}{ Supplier } \\
\hline & & Western blot & Immunofluorescence & \\
\hline Alexa Flur 488 goat anti-rabbit & A-11008 & & $1 / 400$ & Molecular Probes; Thermo \\
\hline $\operatorname{IgG}(\mathrm{H}+\mathrm{L})$ & & & & Fisher Scientific, Inc. \\
\hline Anti-mouse IgG, HRP-linked & 7076 & $1 / 1000$ & & CST \\
\hline Anti-IgG (H+L chain) rabbit & 458 & $1 / 10000$ & & Molecular and Biological \\
\hline pAb-HRP & & & & Laboratories Co., Ltd. \\
\hline Goat anti-mouse HRP & ab97023 & $1 / 1000$ & & Abcam \\
\hline
\end{tabular}

CST, Cell Signaling Technology, Inc.; p, phosphorylated.

confocal laser-scanning microscope (LSM780; Zeiss AG). The primary and secondary antibodies are listed in Table I.

RNA analysis. RNA-Sequencing (RNA-Seq) libraries were generated using RNA extracted from the HCM-MEC010 cell line, as previously described (27), with the TruSeq Stranded mRNA Library Prep kit for Illumina, Inc., following the manufacturer's instructions, then sequenced on a NovaSeq 6000 System (Illumina, Inc.). The analysis was performed by Takara Bio, Inc.

Hematoxylin and eosin-staining. A section of the hard palate was fixed in $10 \%$ formalin solution at room temperature for $24 \mathrm{~h}$ and embedded in paraffin. Sections (5- $\mu \mathrm{m}$ thick) were cut from the paraffin blocks and stained with hematoxylin $(0.09 \%)$ for $5 \mathrm{~min}$ and eosin $(0.13 \%)$ for $9 \mathrm{~min}$ at room temperature according to standard methods (28). The images were captured using a light microscope (BX51; Olympus Corporation).

Patient. A 45-year-old Japanese female noticed spontaneous dull pain and swelling in her hard palate for 1 month and was referred to Hyogo College of Medicine, Nishinomiya, Hyogo, Japan on January, 2019. On examination, diffuse swelling was observed in the right hard palate. There was no trismus. The surface of the mass was smooth and was soft on palpation (Fig. 1A). Bilateral cervical lymph nodes were palpable, but painless and mobile. Magnetic resonance imaging showed an irregular mass measuring 30x20x18 mm in the right hard palate, and resorption in the nasal septum and posterior wall of the maxillary sinus (Fig. 1B). The clinical diagnosis was a malignant tumor of the hard palate. A biopsy was performed intraorally and the lesion was pathologically diagnosed as low-grade MEC using Armed Forces Institute of Pathology (29).

\section{Results}

The patient was admitted to Hyogo College of Medicine, Nishinomiya, Hyogo, Japan and treated by partial resection of the hard palate, supraomohyoid neck dissection and reconstruction using an anterolateral thigh flap under general anesthesia. Hematoxylin and eosin-stained tumor tissue microscopically showed an overlying stratified squamous epithelium, mucous cells and squamous cells that were polygonal-to-ovoid in shape with eosinophilic cytoplasms (Fig. 1C). The mucous cells were cuboidal or goblet-like and tended to line the cysts. The 


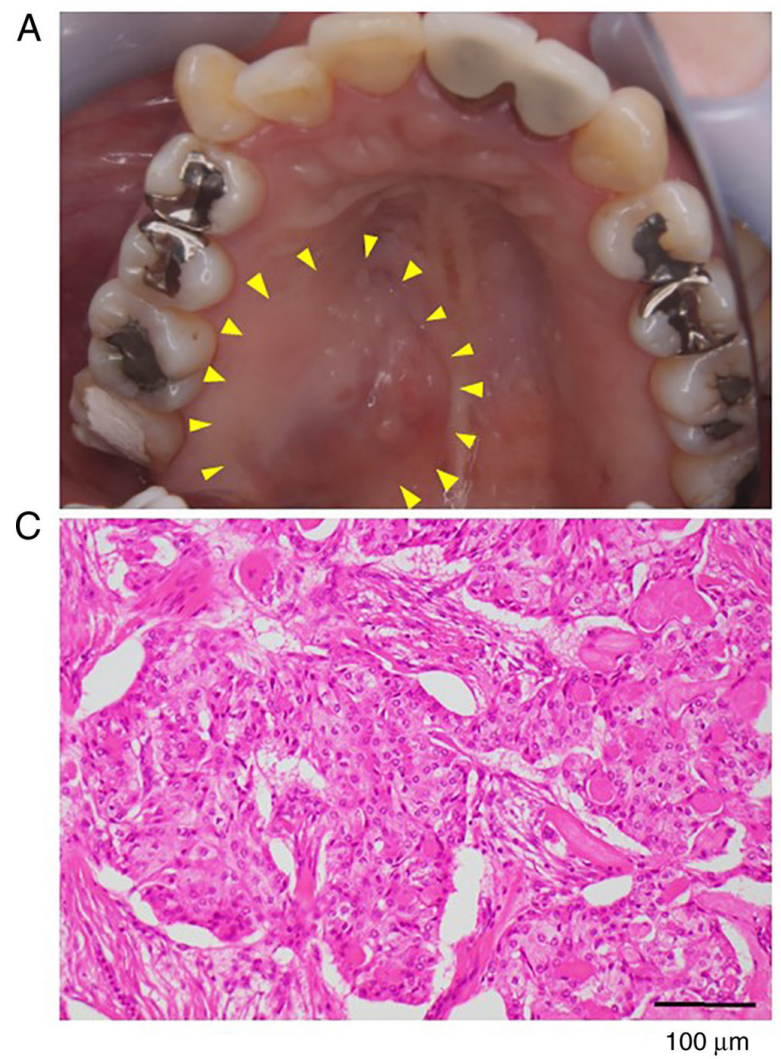

B

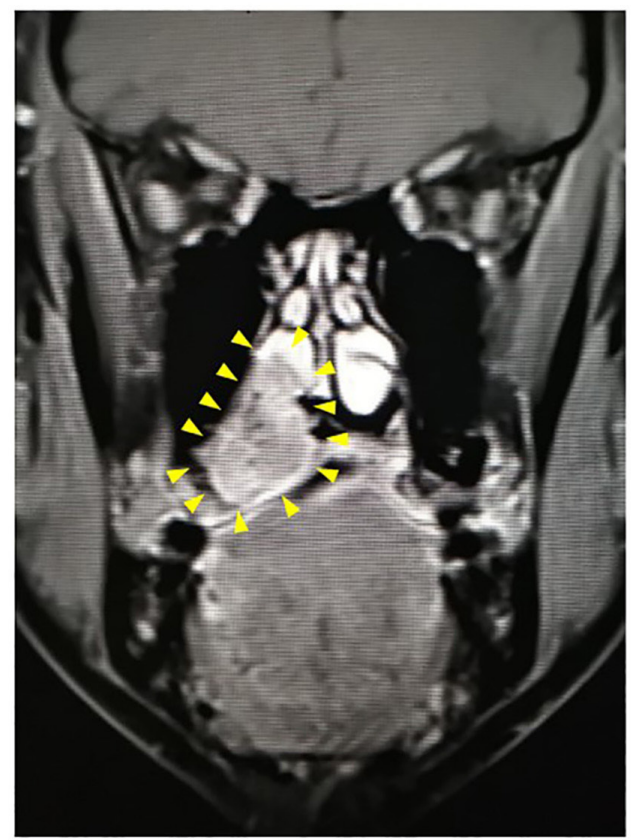

Figure 1. Clinical findings. (A) Normal-colored volumetric tissue with a smooth surface $\sim 30 \times 20 \mathrm{~mm}$ in diameter located on the right side of the hard palate (yellow arrowheads). (B) Magnetic resonance imaging showing an irregular mass measuring 30x20x18 $\mathrm{mm}$ in the right hard palate and resorption in the nasal septum and posterior wall of the maxillary sinus (yellow arrowheads). (C) Microscopic view showing epidermal cells with very few mucous cells and minimal cystic changes suggestive of mucoepidermoid carcinoma with hematoxylin and eosin staining.

squamous cells formed solid sheets. The tumor was diagnosed as mucoepidermoid carcinoma, low-grade type, pT4aN0M0 MEC of the hard palate. All dissected cervical lymph nodes showed no metastatic cells. At the 30-month follow up, the patient's prognosis was excellent and she had maintained a disease-free status.

Establishment of a MEC cell line from a patient tumor. A new MEC cell line, termed HCM-MEC010 was established, which maintained a cobblestone epithelial-like morphology for at least 30 passages (Fig. 2A and B). To confirm that the HCM-MEC010 cell line was derived from the tumor sample of the patient, STR profiling was performed using the DNA extracted from the high-passage HCM-MEC010 cell line and the blood from the patient. Genotypic analysis confirmed that the cell line was derived from the tumor and no contamination with other cell types was detected $(\mathrm{EV}, 1.0)$. (Table SI; Figs. S1 and S2).

RT-PCR analysis reveals that HCM-MECO10 cells express the CRTC1-MAML2 fusion gene. As the CRTC1-MAML2 gene fusion is common in MEC (9), the fusion event was analyzed in the HCM-MEC010 cell line using RT-PCR. Fig. 3A shows the translocation event between chromosomes 11 and 19, while Fig. 3B shows the RT-PCR amplified fragments (lane 1, $101 \mathrm{bp}$ and lane 2, $196 \mathrm{bp}$ ) using primer sets 1 or 2, respectively. The fusion transcript of $C R T C 1$ and MAML2 genes was confirmed using Sanger sequencing (Fig. 3C). This revealed the fusion products of CRTC1 exon 1 and MAML2 exon 2 with the predicted splicing event, indicating that a translocation event had occurred between the first introns of CRTC1 and MAML2.

Protein expression in the HCM-MEC010 cell line. Next, the protein expression of the epithelial and mesenchymal markers in the HCM-MEC010 cell line was confirmed using immunofluorescent staining. EGFR and E-cadherin were expressed on the cell membrane in the HCM-MEC010 cells, while $\mathrm{N}$-cadherin expression was only faintly detected. Vimentin expression was also detected in HCM-MEC010 cells (Fig. 4).

HCM-MEC010 cells express AREG and show EGFR activation. As the AREG-EGFR signaling cascade has been identified as a CRTC1-MAML2 fusion gene target (18), AREG expression and the status of the EGFR cascade was analyzed in the HCM-MEC010 cell line. The human tongue SAS cell line was used as a comparison as the SAS cell line contains a mutation in the HER4 gene, which encodes one of the other types of human EGFR, and the authentic EGFR pathway is not involved in cell proliferation (30). EGFR was expressed in both cell types, but the AREG expression level was much higher in the HCM-MEC010 cell line compared with that in the SAS cell line (Fig. 5). Furthermore, EGFR was phosphorylated (p) in the HCM-MEC010 cell line compared with that in the SAS cell line, indicating the activation of the EGFR pathway. In addition, the expression level of AKT and p-AKT was lower in the HCM-MEC010 cell line 
A

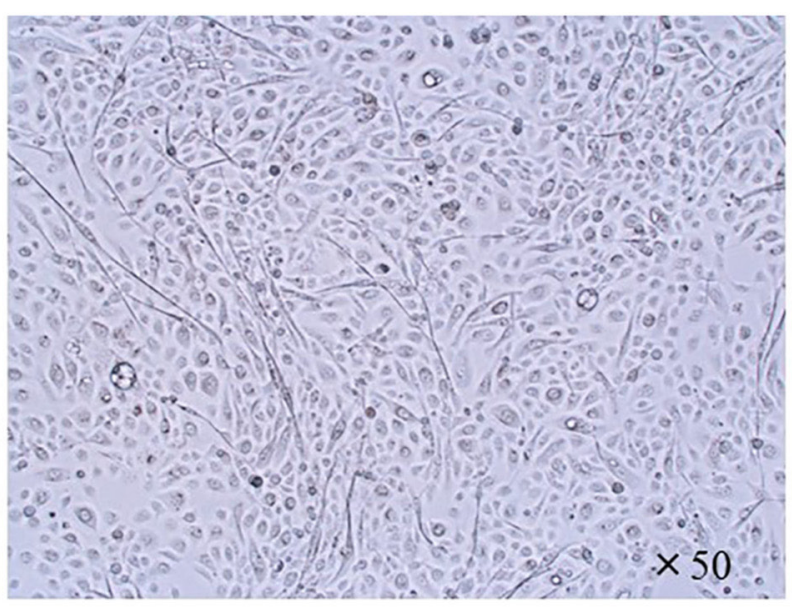

B

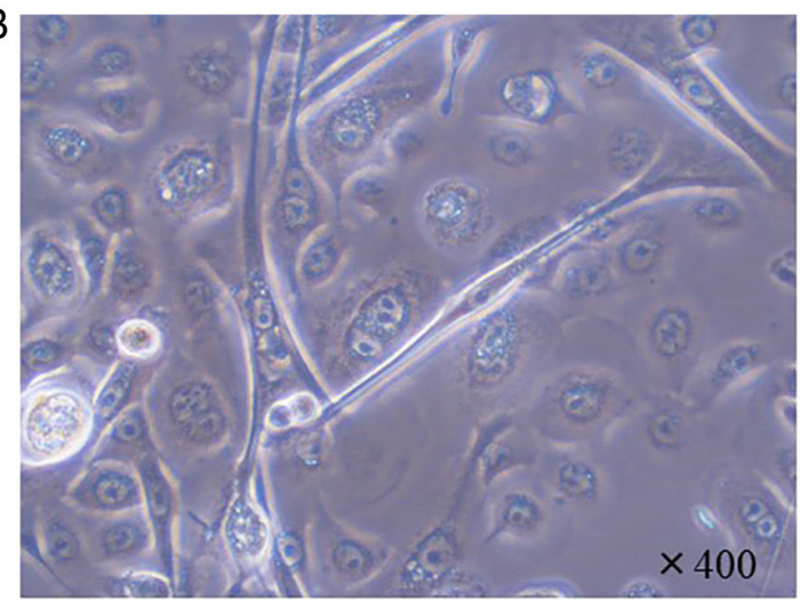

Figure 2. Morphology of the established HCM-MEC010 cells. Microscopic findings of the MEC cell line under (A) low power and (B) high power. MEC, mucoepidermoid carcinoma.
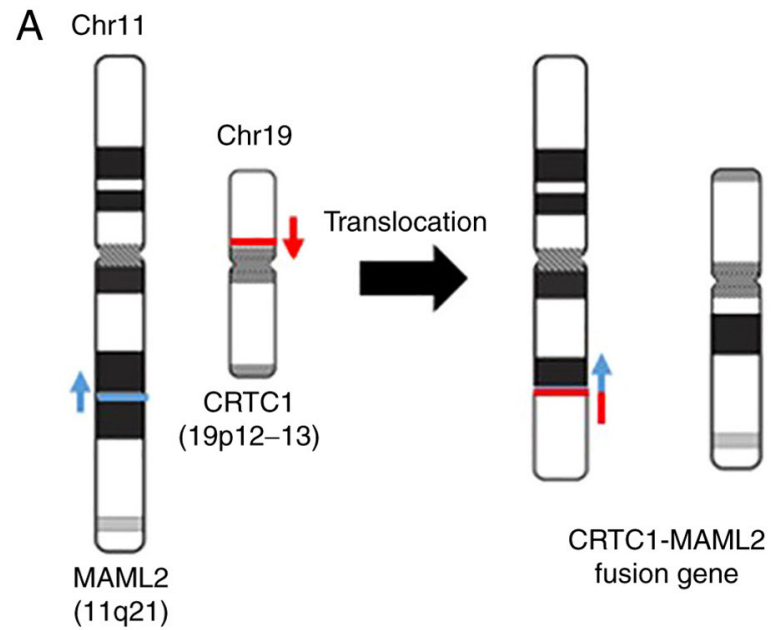

B
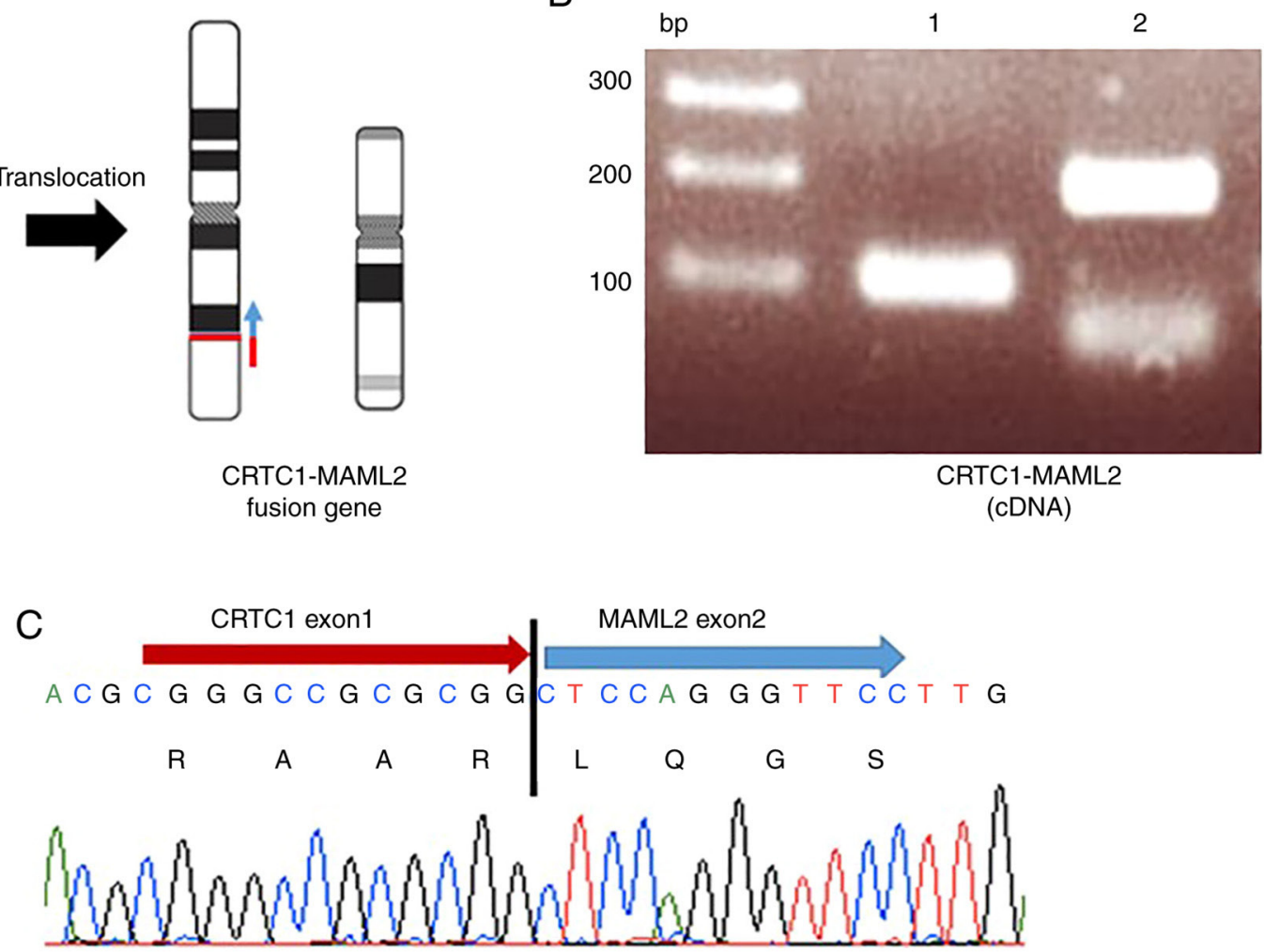

Figure 3. Gene structure of the identified CRTC1-MAML2 fusion gene. (A) Schematic of CRTC1-MAML2 gene fusion. (B) Reverse transcription-PCR analysis showing the presence of a CRTCl-MAML2 fusion transcript. A $101 \mathrm{bp}$ fragment (lane 1) and $194 \mathrm{bp}$ fragment (lane 2) can be seen. (C) Direct sequencing of the CRTC1-MAML2 fusion gene in the mucoepidermoid carcinoma cell line. CRTC1, CREB-regulated transcription coactivator 1; MAML2, Notch coactivator mastermind-like gene 2 .

compared with that in the SAS cell line. In the SAS cell line, AKT can be phosphorylated by both the AREG-EGFR and HER4 pathways $(31,32)$, and high levels of AKT phosphorylation in the SAS cell line must represent an additive effect of HER4 pathway activation (33). E-cadherin was expressed at higher levels in the HCM-MEC010 cell line compared with that in the SAS cell line. Vimentin expression was detected in small amounts in both the HCM-MEC010 and SAS cell lines (Fig. 5).
RNA-seq analysis of the HCM-MECO10 cell line revealed epidermoid characteristics. To further characterize the HCM-MEC010 cell line, RNA-Seq analysis was performed. MEC is known to be composed of a mixture of mucous, epidermoid, and intermediate cells (34). RNA-Seq analysis revealed the high expression level of genes in the keratin family, including KRT5, KRT14, KRT6A, KRT17, and KRT7. Table II lists the top 200 expressed genes. However, expression of the mucous cell marker $M U C$ was not detected. These 

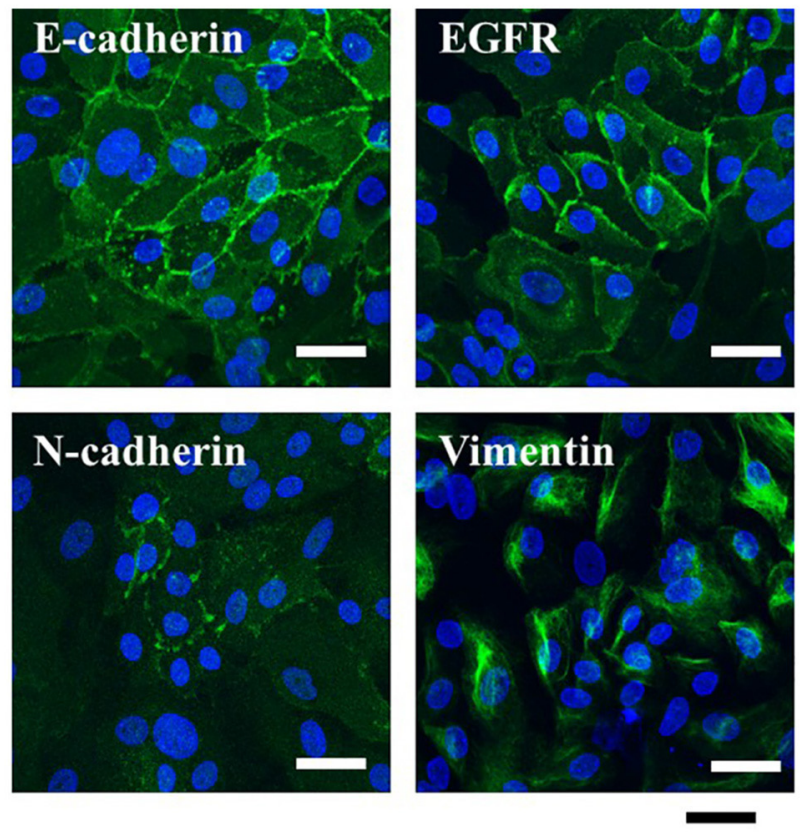

$20 \mu \mathrm{m}$
A

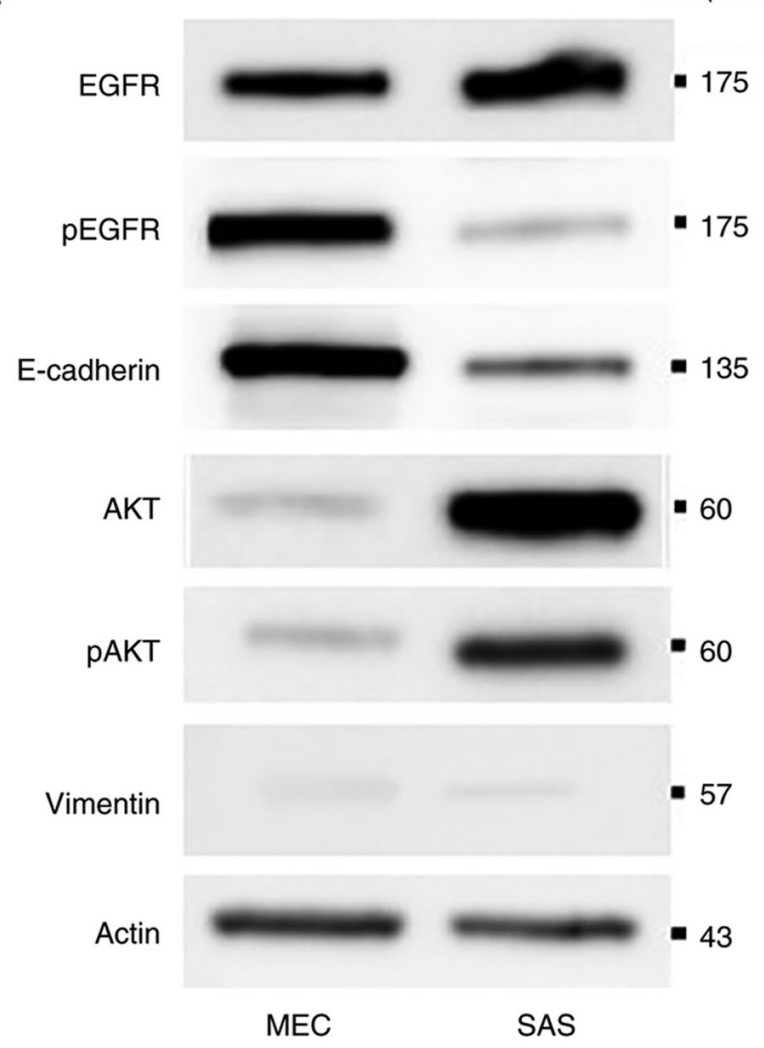

B
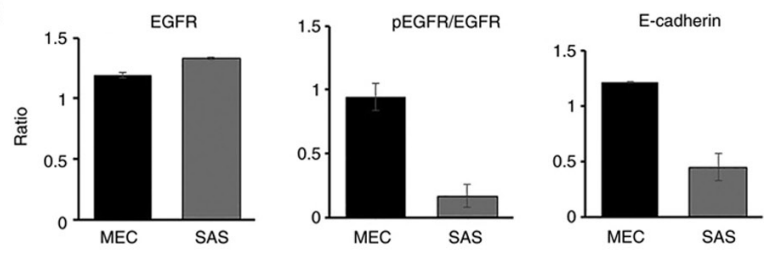

The isolation of primary tumor cells from patient samples is the first step for several genetic, biochemical and pharmacological experiments relevant to personalized cancer treatment (35). However, such studies are limited due to cell availability. The establishment of a cancer cell line is a traditional, but still powerful and informative method of studying human cancer. The present study reports the establishment of a MEC cell line with a CRTC1-MAML2 fusion gene.

Several studies have shown that the presence of the CRTC1/3-MAML2 fusion gene confers an improved prognosis, with improved disease-free survival and fewer distant metastasis in MEC $(36,37)$. There are rare exceptions to this rule, including fusion-positive high-grade MEC with multiple additional genetic variations, such as mutations in $C D K N 2 \mathrm{~A}$, that have been associated with a poor prognosis (38).

The function of the CRTC1-MAML2 fusion gene has been intensively studied. Its transformation ability was identified using the RK3E cell line (39) and its importance for tumor state maintenance has also been demonstrated. Initially, it was hypothesized to cause tumor growth by the constitutive activation of Notch signaling via the MAML2 gene portion. Furthermore, the $\mathrm{N}$ terminus CRTC1 domain-mediated aberrant activation of cAMP/CREB signaling has also been identified as a cause of tumor formation $(14,40)$. The interaction between AP-1 and MYC oncoprotein with CRTC1-MAML2 fusion proteins has been reported (41), suggesting that the CRTC1-MAML2 fusion gene regulates several different
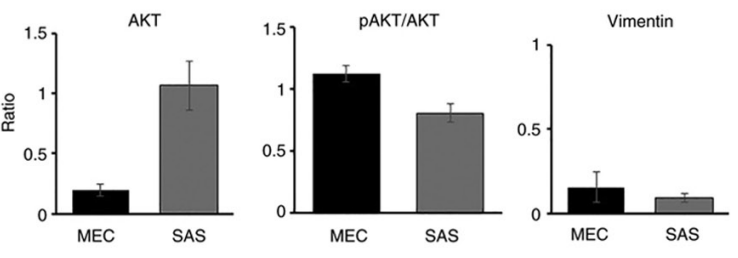

C

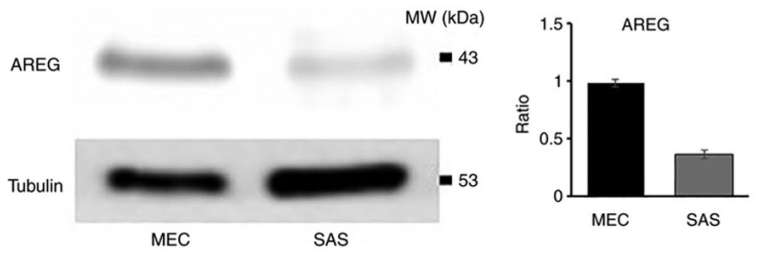

Figure 5. Western blot analysis of EGFR-AKT signaling in the HCM-MEC010 and SAS cell lines. (A) Western blot analysis of EGFR, p-EGFR, E-cadherin, AKT, p-AKT, vimentin and actin and the results were (B) analyzed using densitometry. (C) Western blot analysis of AREG and tubulin. MEC, mucoepidermoid carcinoma; $p$, phosphorylated.

signaling pathways. AREG is a known cAMP/CREB-regulated gene, whose expression positively correlates with that of CRTC1-MAML2 in MEC (42). As AREG-EGFR signaling was identified as one of the CRTC1-MAML2 fusion gene targets, EGFR signaling could represent the mechanism of action by which the fusion gene promotes carcinogenesis. 
Table II. RNA-Sequencing data for the MEC cell line.

\begin{tabular}{|c|c|c|c|}
\hline Entrez gene ID & Gene symbol & Description & TPM \\
\hline 6280 & S100A9 & S100 calcium binding protein A9 & 25012.1582 \\
\hline- & RNR2 & - & 19355.6582 \\
\hline 6277 & S100A6 & S100 calcium binding protein A6 & 15991.2832 \\
\hline 1915 & EEF1A1 & Eukaryotic translation elongation factor $1 \alpha 1$ & 13189.91406 \\
\hline 9168 & TMSB10 & Thymosin $\beta 10$ & 11790.02637 \\
\hline 3852 & KRT5 & Keratin 5 & 10268.93652 \\
\hline 6590 & SLPI & Secretory leukocyte peptidase inhibitor & 9873.083008 \\
\hline 6222 & RPS18 & Ribosomal protein S18 & 9865.65332 \\
\hline 3861 & KRT14 & Keratin 14 & 9010.899414 \\
\hline 301 & ANXA1 & Annexin A1 & 8724.607422 \\
\hline 302 & ANXA2 & Annexin A2 & 8183.348633 \\
\hline 6130 & RPL7A & Ribosomal protein $17 \mathrm{a}$ & 7233.334961 \\
\hline 3853 & KRT6A & Keratin 6A & 7038.019531 \\
\hline 6205 & RPS11 & Ribosomal protein S11 & 6782.036133 \\
\hline 3872 & KRT17 & Keratin 17 & 6779 \\
\hline 6282 & S100A11 & $\mathrm{S} 100$ calcium binding protein $\mathrm{A} 11$ & 6758.137695 \\
\hline 57402 & S100A14 & S100 calcium binding protein A14 & 6577.536133 \\
\hline 6136 & RPL12 & Ribosomal protein L12 & 6571.3125 \\
\hline 6202 & RPS8 & Ribosomal protein $\mathrm{S} 8$ & 5322.165039 \\
\hline 23521 & RPL13A & Ribosomal protein $113 \mathrm{a}$ & 5300.688477 \\
\hline 6175 & RPLP0 & Ribosomal protein lateral stalk subunit P0 & 5200.693848 \\
\hline 6144 & RPL21 (2) & Ribosomal protein L21 & 5167.824219 \\
\hline 7114 & TMSB4X & Thymosin $\beta 4$ X-linked & 4858.939453 \\
\hline 6201 & RPS7 & Ribosomal protein S7 & 4807.380371 \\
\hline 6281 & S100A10 & S100 calcium binding protein A10 & 4705.583984 \\
\hline 6206 & RPS12 & Ribosomal protein $\mathrm{S} 12$ & 4461.196777 \\
\hline 6230 & RPS25 & Ribosomal protein $\mathrm{S} 25$ & 4362.669922 \\
\hline 6122 & RPL3 & Ribosomal protein L3 & 4190.952148 \\
\hline 2597 & GAPDH & Glyceraldehyde-3-phosphate dehydrogenase & 4084.755371 \\
\hline 4502 & MT2A & Metallothionein 2A & 4024.866699 \\
\hline 3855 & KRT7 & Keratin 7 & 3954.171631 \\
\hline 6194 & RPS6 & Ribosomal protein S6 & 3893.395996 \\
\hline 6152 & RPL24 & Ribosomal protein L24 & 3876.068848 \\
\hline 6142 & RPL18A & Ribosomal protein $118 \mathrm{a}$ & 3788.035645 \\
\hline 60 & ACTB & $\operatorname{Actin} \beta$ & 3734.336914 \\
\hline 6156 & RPL30 & Ribosomal protein L30 & 3719.687988 \\
\hline 6279 & S100A8 & S100 calcium binding protein A8 & 3664.906982 \\
\hline 10399 & RACK1 & Receptor for activated $\mathrm{C}$ kinase 1 & 3650.605225 \\
\hline 100133941 & CD24 & CD24 molecule & 3593.078369 \\
\hline 6191 & RPS4X & Ribosomal protein S4 X-linked & 3478.193848 \\
\hline- & RNR1 & - & 3421.098877 \\
\hline 2950 & GSTP1 & Glutathione S-transferase pi 1 & 3338.100586 \\
\hline 6187 & RPS2 & Ribosomal protein $\mathrm{S} 2$ & 3280.663086 \\
\hline 6207 & RPS13 & Ribosomal protein S13 & 3170.464111 \\
\hline 11224 & RPL35 & Ribosomal protein L35 & 3153.293701 \\
\hline 1937 & EEF1G & Eukaryotic translation elongation factor $1 \gamma$ & 3140.122559 \\
\hline 6125 & RPL5 & Ribosomal protein L5 & 3137.963623 \\
\hline 6170 & RPL39 & Ribosomal protein L39 & 3100.071045 \\
\hline 4637 & MYL6 & Myosin light chain 6 & 3067.146484 \\
\hline 3868 & KRT16 & Keratin 16 & 3044.359619 \\
\hline 4736 & RPL10A & Ribosomal protein $110 \mathrm{a}$ & 2961.195801 \\
\hline 6141 & RPL18 & Ribosomal protein L18 & 2929.649658 \\
\hline
\end{tabular}


Table II. Continued.

\begin{tabular}{|c|c|c|c|}
\hline Entrez gene ID & Gene symbol & Description & TPM \\
\hline 1476 & CSTB & Cystatin B & 2910.897217 \\
\hline 6124 & RPL4 & Ribosomal protein L4 & 2865.387207 \\
\hline 4070 & TACSTD2 & Tumor associated calcium signal transducer 2 & 2787.421387 \\
\hline 6147 & RPL23A & Ribosomal protein $123 \mathrm{a}$ & 2730.734131 \\
\hline 71 & ACTG1 & Actin $\gamma 1$ & 2705.085693 \\
\hline 220 & ALDH1A3 & Aldehyde dehydrogenase 1 family member A3 & 2588.035156 \\
\hline 6135 & RPL11 & Ribosomal protein L11 & 2561.839844 \\
\hline 3880 & KRT19 & Keratin 19 & 2536.187012 \\
\hline 6132 & RPL8 & Ribosomal protein L8 & 2522.498047 \\
\hline 6181 & RPLP2 & Ribosomal protein lateral stalk subunit $\mathrm{P} 2$ & 2490.632813 \\
\hline 3866 & KRT15 & Keratin 15 & 2464.382324 \\
\hline 6699 & SPRR1B & Small proline rich protein $1 \mathrm{~B}$ & 2444.126465 \\
\hline 6159 & RPL29 & Ribosomal protein L29 & 2439.016113 \\
\hline 2512 & FTL & Ferritin light chain & 2432.441895 \\
\hline 6193 & RPS5 & Ribosomal protein S5 & 2432.29126 \\
\hline 6233 & RPS27A & Ribosomal protein s27a & 2403.434326 \\
\hline 6129 & RPL7 & Ribosomal protein L7 & 2332.271973 \\
\hline 6273 & S100A2 & S100 calcium binding protein $\mathrm{A} 2$ & 2289.59375 \\
\hline 6133 & RPL9 & Ribosomal protein L9 & 2237.880371 \\
\hline 1475 & CSTA & Cystatin A & 2159.565186 \\
\hline 6128 & RPL6 & Ribosomal protein L6 & 2119.131592 \\
\hline 2495 & FTH1 & Ferritin heavy chain 1 & 2094.474121 \\
\hline 3921 & RPSA & Ribosomal protein SA & 2085.400391 \\
\hline 5266 & PI3 & Peptidase inhibitor 3 & 2079.049805 \\
\hline 2171 & FABP5 & Fatty acid binding protein 5 & 2073.613281 \\
\hline 5052 & PRDX1 & Peroxiredoxin 1 & 2053.132568 \\
\hline 3956 & LGALS1 & Galectin 1 & 2031.178833 \\
\hline 6143 & RPL19 & Ribosomal protein L19 & 2021.314087 \\
\hline 25818 & KLK5 & Kallikrein related peptidase 5 & 1822.719238 \\
\hline 3939 & LDHA & Lactate dehydrogenase A & 1803.661499 \\
\hline 6176 & RPLP1 & Ribosomal protein lateral stalk subunit P1 & 1802.172241 \\
\hline 51458 & RHCG & Rh family C glycoprotein & 1785.147339 \\
\hline 6303 & SAT1 & Spermidine/spermine N1-acetyltransferase 1 & 1763.299316 \\
\hline 9982 & FGFBP1 & Fibroblast growth factor binding protein 1 & 1742.557251 \\
\hline 7178 & TPT1 & Tumor protein, translationally-controlled 1 & 1741.52832 \\
\hline 6227 & RPS21 & Ribosomal protein S21 & 1726.189087 \\
\hline 3934 & LCN2 & Lipocalin 2 & 1720.297241 \\
\hline 3315 & HSPB1 & Heat shock protein family B (small) member 1 & 1668.157104 \\
\hline 1973 & EIF4A1 & Eukaryotic translation initiation factor $4 \mathrm{~A} 1$ & 1623.40625 \\
\hline 1938 & EEF2 & Eukaryotic translation elongation factor 2 & 1612.361694 \\
\hline 5055 & SERPINB2 & Serpin family B member 2 & 1610.25 \\
\hline 2810 & SFN & Stratifin & 1591.703979 \\
\hline 6703 & SPRR2D & Small proline rich protein $2 \mathrm{D}$ & 1568.223389 \\
\hline 26986 & PABPC1 & Poly(A) binding protein cytoplasmic 1 & 1534.452637 \\
\hline 6204 & RPS10 & Ribosomal protein S10 & 1532.445679 \\
\hline 10410 & IFITM3 & Interferon induced transmembrane protein 3 & 1529.12146 \\
\hline 6189 & RPS3A & Ribosomal protein S3A & 1509.361816 \\
\hline 6154 & RPL26 & Ribosomal protein L26 & 1432.493286 \\
\hline 3918 & LAMC2 & Laminin subunit $\gamma 2$ & 1429.380249 \\
\hline 83442 & SH3BGRL3 & SH3 domain binding glutamate rich protein like 3 & 1395.721313 \\
\hline 6139 & RPL17 & Ribosomal protein L17 & 1375.231934 \\
\hline
\end{tabular}


Table II. Continued.

\begin{tabular}{|c|c|c|c|}
\hline Entrez gene ID & Gene symbol & Description & TPM \\
\hline 1933 & EEF1B2 & Eukaryotic translation elongation factor $1 \beta 2$ & 1351.424194 \\
\hline 10974 & ADIRF & Adipogenesis regulatory factor & 1348.772461 \\
\hline 6134 & RPL10 & Ribosomal protein L10 & 1336.026611 \\
\hline 5268 & SERPINB5 & Serpin family B member 5 & 1335.237183 \\
\hline 6700 & SPRR2A & Small proline rich protein $2 \mathrm{~A}$ & 1285.784912 \\
\hline 10094 & ARPC3 & Actin related protein $2 / 3$ complex subunit 3 & 1270.268311 \\
\hline 2152 & $\mathrm{~F} 3$ & Coagulation factor III, tissue factor & 1268.36792 \\
\hline 2197 & FAU & FAU ubiquitin like and ribosomal protein S30 fusion & 1255.56189 \\
\hline 9124 & PDLIM1 & PDZ and LIM domain 1 & 1252.652954 \\
\hline 64065 & PERP & P53 apoptosis effector related to PMP22 & 1252.282227 \\
\hline 4869 & NPM1 & Nucleophosmin 1 & 1247.643188 \\
\hline 7295 & TXN & Thioredoxin & 1169.833984 \\
\hline 3553 & IL1B & Interleukin $1 \beta$ & 1166.45752 \\
\hline 5054 & SERPINE1 & Serpin family E member 1 & 1154.025146 \\
\hline 6171 & RPL41 & Ribosomal protein L41 & 1152.395996 \\
\hline 25824 & PRDX5 & Peroxiredoxin 5 & 1133.30603 \\
\hline 6173 & RPL36A & Ribosomal protein $136 \mathrm{a}$ & 1111.359619 \\
\hline 5315 & PKM & Pyruvate kinase M1/2 & 1092.81897 \\
\hline 1072 & CFL1 & Cofilin 1 & 1085.361328 \\
\hline 6289 & SAA2 & Serum amyloid A2 & 1073.526978 \\
\hline 4071 & TM4SF1 & Transmembrane 4 L six family member 1 & 1063.068237 \\
\hline 506 & ATP5F1B & ATP synthase F1 subunit $\beta$ & 1047.457275 \\
\hline 5834 & PYGB & Glycogen phosphorylase B & 1047.218994 \\
\hline 928 & CD9 & CD9 molecule & 1021.081299 \\
\hline 10628 & TXNIP & Thioredoxin interacting protein & 1021.076111 \\
\hline 103910 & MYL12B & Myosin light chain 12B & 1012.033325 \\
\hline 3854 & KRT6B & Keratin $6 \mathrm{~B}$ & 1011.945374 \\
\hline 3688 & ITGB 1 & Integrin subunit $\beta 1$ & 1004.073792 \\
\hline 3312 & HSPA8 & Heat shock protein family A (Hsp70) member 8 & 1000.302063 \\
\hline 6288 & SAA1 & Serum amyloid A1 & 999.111145 \\
\hline 1382 & CRABP2 & Cellular retinoic acid binding protein 2 & 986.4415283 \\
\hline 6224 & RPS20 & Ribosomal protein S20 & 975.680481 \\
\hline 10109 & ARPC2 & Actin related protein $2 / 3$ complex subunit 2 & 966.9124146 \\
\hline 1992 & SERPINB1 & Serpin family B member 1 & 952.090332 \\
\hline 306 & ANXA3 & Annexin A3 & 951.5344238 \\
\hline 4501 & MT1X & Metallothionein $1 \mathrm{X}$ & 939.5453491 \\
\hline 5660 & PSAP & Prosaposin & 936.7683105 \\
\hline 6286 & S100P & S100 calcium binding protein $\mathrm{P}$ & 924.9679565 \\
\hline 567 & B2M & $\beta$-2-microglobulin & 919.1690674 \\
\hline 3914 & LAMB3 & Laminin subunit $\beta 3$ & 918.9204102 \\
\hline 1308 & COL17A1 & Collagen type XVII $\alpha 1$ chain & 916.5231323 \\
\hline 824 & CAPN2 & Calpain 2 & 912.717041 \\
\hline 2706 & GJB2 & Gap junction protein $\beta 2$ & 904.8463745 \\
\hline 3860 & KRT13 & Keratin 13 & 894.9153442 \\
\hline 3646 & EIF3E & Eukaryotic translation initiation factor 3 subunit E & 893.5683594 \\
\hline 5479 & PPIB & Peptidylprolyl isomerase B & 883.137207 \\
\hline 7316 & UBC & Ubiquitin C & 875.6885986 \\
\hline 3326 & HSP90AB1 & Heat shock protein $90 \alpha$ family class B member 1 & 871.9744263 \\
\hline 642587 & MIR205HG & MIR205 host gene & 864.2874146 \\
\hline 468 & ATF4 & Activating transcription factor 4 & 850.9224243 \\
\hline 140576 & S100A16 & S100 calcium binding protein A16 & 849.9338989 \\
\hline 6155 & RPL27 & Ribosomal protein L27 & 841.65802 \\
\hline
\end{tabular}


Table II. Continued.

\begin{tabular}{|c|c|c|c|}
\hline Entrez gene ID & Gene symbol & Description & TPM \\
\hline 6228 & RPS23 & Ribosomal protein S23 & 837.4863281 \\
\hline 25984 & KRT23 & Keratin 23 & 837.0656738 \\
\hline 54541 & DDIT4 & DNA damage inducible transcript 4 & 831.8173218 \\
\hline 112694756 & LOC112694756 & Uncharaterized LOC112694756 & 831.1845093 \\
\hline 9349 & RPL23 & Ribosomal protein L23 & 826.6482544 \\
\hline 7184 & HSP90B1 & Heat shock protein $90 \beta$ family member 1 & 826.4506836 \\
\hline 1337 & COX6A1 & Cytochrome $\mathrm{c}$ oxidase subunit $6 \mathrm{~A} 1$ & 820.6051025 \\
\hline 1974 & EIF4A2 & Eukaryotic translation initiation factor $4 \mathrm{~A} 2$ & 800.7364502 \\
\hline 6188 & RPS3 & Ribosomal protein S3 & 796.1228638 \\
\hline 6157 & RPL27A & Ribosomal protein $127 \mathrm{a}$ & 790.3303833 \\
\hline 5757 & PTMA & Prothymosin $\alpha$ & 790.0863037 \\
\hline 826 & CAPNS1 & Calpain small subunit 1 & 783.6133423 \\
\hline 5328 & PLAU & Plasminogen activator, urokinase & 780.4100342 \\
\hline 2023 & ENO1 & Enolase 1 & 778.8522949 \\
\hline 1509 & CTSD & Cathepsin D & 771.4251709 \\
\hline 10476 & ATP5PD & ATP synthase peripheral stalk subunit d & 768.3088989 \\
\hline 7534 & YWHAZ & $\begin{array}{l}\text { Tyrosine 3-monooxygenase/tryptophan } \\
5 \text {-monooxygenase activation protein } \zeta\end{array}$ & 767.7701416 \\
\hline 292 & SLC25A5 & Solute carrier family 25 member 5 & 758.4469604 \\
\hline 5216 & PFN1 & Profilin 1 & 753.312439 \\
\hline 1340 & COX6B1 & Cytochrome $\mathrm{c}$ oxidase subunit $6 \mathrm{~B} 1$ & 751.3442383 \\
\hline 8407 & TAGLN2 & Transgelin 2 & 741.7597046 \\
\hline 689 & BTF3 & Basic transcription factor 3 & 738.1211548 \\
\hline 374 & AREG & Amphiregulin & 735.1116333 \\
\hline 10376 & TUBA1B & Tubulin $\alpha 1 b$ & 732.8063965 \\
\hline 6210 & RPS15A & Ribosomal protein s15a & 728.9209595 \\
\hline 3909 & LAMA3 & Laminin subunit $\alpha 3$ & 723.6885986 \\
\hline 7086 & TKT & Transketolase & 713.4926147 \\
\hline 5650 & KLK7 & Kallikrein related peptidase 7 & 708.7366333 \\
\hline 4323 & MMP14 & Matrix metallopeptidase 14 & 702.4146118 \\
\hline 4312 & MMP1 & Matrix metallopeptidase 1 & 700.8983154 \\
\hline 6229 & RPS24 & Ribosomal protein S24 & 700.0944824 \\
\hline 10653 & SPINT2 & Serine peptidase inhibitor, Kunitz type 2 & 695.8338623 \\
\hline 4831 & NME2 & NME/NM23 nucleoside diphosphate kinase 2 & 694.8643799 \\
\hline 10971 & YWHAQ & $\begin{array}{l}\text { Tyrosine 3-monooxygenase/tryptophan } \\
5 \text {-monooxygenase activation protein } \tau\end{array}$ & 692.3873291 \\
\hline 5478 & PPIA & Peptidylprolyl isomerase A & 682.8765869 \\
\hline 7980 & TFPI2 & Tissue factor pathway inhibitor 2 & 679.0671997 \\
\hline 6146 & RPL22 & Ribosomal protein L22 & 678.4135132 \\
\hline 3945 & LDHB & Lactate dehydrogenase B & 671.2799683 \\
\hline 351 & APP & Amyloid $\beta$ precursor protein & 665.9901733 \\
\hline 1508 & CTSB & Cathepsin B & 665.0159302 \\
\hline 10209 & EIF1 & Eukaryotic translation initiation factor 1 & 664.9918213 \\
\hline 8673 & VAMP8 & Vesicle associated membrane protein 8 & 659.6922607 \\
\hline 7416 & VDAC1 & Voltage dependent anion channel 1 & 659.1289063 \\
\hline 4946 & OAZ1 & Ornithine decarboxylase antizyme 1 & 656.2600098 \\
\hline 6168 & RPL37A & Ribosomal protein $137 \mathrm{a}$ & 649.401123 \\
\hline
\end{tabular}

TPM, transcript per million. 
These observations suggest an overall role for EGFR in the pathogenesis of MEC and the EGFR pathway could be a possible therapeutic target. As several drugs target this pathway, AREG-EGFR signaling was analyzed in the HCM-MEC010 cell line in the present study. The HCM-MEC010 cell line was found to express AREG and phosphorylate EGFR. Immunofluorescence analysis localized EGFR expression to the HCM-MEC010 cell membrane. These data suggest that the EGFR ligand, AREG, activated EGFR in an autocrine manner; therefore, antibodies that block AREG-EGFR binding or drugs that interfere with EGFR activation could be used for CRTC1-MAML2 fusion-positive MEC treatment. However, further analysis is required to identify suitable therapies.

MECs are composed of mucin-producing, epidermoid, and intermediate cells; however, RNA-Seq analysis of the HCM-MEC010 cell line detected little expression of $M U C$ genes in the mucous cell marker family, indicating that mucin-producing cells and intermediate cells may have been removed during culture. MECs develop in excretory duct cells (43) and the mixture of three different cell types in MECs predicts their common origin. Duct and acinar cell differentiation are typically lineage-restricted; however, after irradiation, both duct and acinar cells can differentiate into different cell types (44). It is conceivable that established epidermoid-like cells are competent to differentiate into acinar cells, which is a predicted characteristic of injured duct stem cells. Further analysis will assist in the clarification into the origin of MECs. Cancer stem cells have been hypothesized to be involved in tumor formation (43). The results of the present study potentially indicate these cells may be of the same origin.

In conclusion, a MEC cell line, HCM-MEC010, with a CRTC1-MAML2 gene fusion was established. This cell line showed typical MEC characteristics, including AREG expression and EGFR activation; therefore, it could be used to assist in the identification of EGFR-targeted drugs for the treatment of CRTC1-MAML2 fusion gene-harboring MEC.

\section{Acknowledgements}

The authors would like to thank Ms. Shinobu Osawa (Department of Oral and Maxillofacial Surgery, Hyogo College of Medicine, Nishinomiya, Japan) for preparation of the experiments and Ms. Takako Nanba (Department of Oral and Maxillofacial Surgery, Hyogo College of Medicine, Nishinomiya, Japan) for the management of the grants. The authors would also like to thank Nikki March and Sarah Williams for editing a draft version of the manuscript.

\section{Funding}

This study was supported by JSPS Grants-in-Aid for Scientific Research (grant nos. 16H11737 and 19H 10277), a Grant-in-Aid for Graduate Students, and a Hyogo College of Medicine and Hyogo Health Foundation Cancer Research Award.

\section{Availability of data and materials}

The datasets generated and/or analyzed during the current study are not publicly available due to a pending patent application, but are available from the corresponding author on reasonable request.

\section{Authors' contributions}

$\mathrm{KN}, \mathrm{SK}, \mathrm{KaY}, \mathrm{KT}, \mathrm{HK}$ and YN conceived and designed the present study. KN, SK, KaY, YF, KyY and YN performed the experiments. KN, SK, KoY and YN analyzed the data. KN, SK and YN wrote, reviewed, and revised the manuscript. All authors read and approved the final manuscript. KN and SK confirm the authenticity of all the raw data.

\section{Ethics approval and consent to participate}

The current study was approved by the Institutional Review Board of Hyogo College of Medicine (Hyogo, Japan) and was conducted in accordance with the Declaration of Helsinki. The patient provided written informed consent to participate.

\section{Patient consent for publication}

The patient provided written informed consent for the publication of their case study.

\section{Competing interests}

The authors declare that they have no competing interests.

\section{References}

1. Sentani K, Ogawa I, Ozawa K, Sadakane A, Utada M, Tsuya T, Kajihara H, Yonehara S, Takeshima Y and Yasui W: Characteristics of 5015 salivary gland neoplasms registered in the Hiroshima tumor tissue registry over a period of 39 years. J Clin Med 8: 566, 2019.

2. Behboudi A, Enlund F, Winnes M, Andrén Y, Nordkvist A, Leivo I, Flaberg E, Szekely L, Mäkitie A, Grenman R, et al: Molecular classification of mucoepidermoid carcinomas-prognostic significance of the MECT1-MAML2 fusion oncogene. Genes Chromosomes Cancer 45: 470-481, 2006.

3. Ettl T, Schwarz-Furlan S, Gosau M and Reichert TE: Salivary gland carcinomas. Oral Maxillofac Surg 16: 267-283, 2012.

4. Katabi N, Ghossein R, Ali S, Dogan S, Klimstra D and Ganly I: Prognostic features in mucoepidermoid carcinoma of major salivary glands with emphasis on tumour histologic grading. Histopathology 65: 793-804, 2014.

5. El-Naggar AK, Lovell M, Killary AM, Clayman GL and Batsakis JG: A mucoepidermoid carcinoma of minor salivary gland with $\mathrm{t}(11 ; 19)(\mathrm{q} 21 ; \mathrm{p} 13.1)$ as the only karyotypic abnormality. Cancer Genet Cytogenet 87: 29-33, 1996.

6. Saade RE, Bell D, Garcia J, Roberts D and Weber R: Role of CRTC1/MAML2 translocation in the prognosis and clinical outcomes of mucoepidermoid carcinoma. JAMA Otolaryngol Head Neck Surg 142: 234-240, 2016.

7. Bell D and El-Naggar AK: Molecular heterogeneity in mucoepidermoid carcinoma: Conceptual and practical implications. Head Neck Pathol 7: 23-27, 2013.

8. Jee KJ, Persson M, Heikinheimo K, Passador-Santos F, Aro K, Knuutila S, Odell EW, Mäkitie A, Sundelin K, Stenman G and Leivo I: Genomic profiles and CRTC1-MAML2 fusion distinguish different subtypes of mucoepidermoid carcinoma. Mod Pathol 26: 213-222, 2013.

9. O'Neill ID: $t(11 ; 19)$ translocation and CRTC1-MAML2 fusion oncogene in mucoepidermoid carcinoma. Oral Oncol 45: 2-9, 2009.

10. Seethala RR, Dacic S, Cieply K, Kelly LM and Nikiforova MN: A reappraisal of the MECT1/MAML2 translocation in salivary mucoepidermoid carcinomas. Am J Surg Pathol 34: 1106-1121, 2010. 
11. Tonon G, Modi S, Wu L, Kubo A, Coxon AB, Komiya T, O'Neil K, Stover K, El-Naggar A, Griffin JD, et al: $\mathrm{t}(11 ; 19)$ (q21;p13) translocation in mucoepidermoid carcinoma creates a novel fusion product that disrupts a Notch signaling pathway. Nat Genet 33: 208-213, 2003.

12. Enlund F, Behboudi A, Andrén Y, Oberg C, Lendahl U, Mark J and Stenman G: Altered Notch signaling resulting from expression of a WAMTP1-MAML2 gene fusion in mucoepidermoid carcinomas and benign Warthin's tumors. Exp Cell Res 292: 21-28, 2004.

13. Wu L, Liu J, Gao P, Nakamura M, Cao Y, Shen H and Griffin JD Transforming activity of MECT1-MAML2 fusion oncoprotein is mediated by constitutive CREB activation. EMBO J 24: 2391-2402, 2005.

14. Coxon A, Rozenblum E, Park YS, Joshi N, Tsurutani J, Dennis PA, Kisch IR and Kaye FJ: Mect1-Maml2 fusion oncogene linked to the aberrant activation of cyclic AMP/CREB regulated genes. Cancer Res 65: 7137-7144, 2005.

15. Fehr A, Röser K, Heidorn K, Hallas C, Löning T and Bullerdiek J: A new type of MAML2 fusion in mucoepidermoid carcinoma. Genes Chromosomes Cancer 47: 203-206, 2008.

16. Okabe M, Miyabe S, Nagatsuka H, Terada A, Hanai N, Yokoi M, Shimozato K, Eimoto T, Nakamura S, Nagai N, et al: MECT1-MAML2 fusion transcript defines a favorable subset of mucoepidermoid carcinoma. Clin Cancer Res 12: 3902-3907, 2006

17. Nakayama T, Miyabe S, Okabe M, Sakuma H, Ijichi K, Hasegawa Y, Nagatsuka H, Shimozato $\mathrm{K}$ and Inagaki $\mathrm{H}$ : Clinicopathological significance of the CRTC3-MAML2 fusion transcript in mucoepidermoid carcinoma. Mod Pathol 22: $1575-1581,2009$.

18. Chen Z, Chen J, Gu Y, Hu C, Li JL, Lin S, Shen H, Cao C, Gao R, Li J, et al: Aberrantly activated AREG-EGFR signaling is required for the growth and survival of CRTC1-MAML2 fusion-positive mucoepidermoid carcinoma cells. Oncogene 33: 3869-3877, 2014.

19. Dahse R, Driemel O, Schwartz S, Dahse J,Kromeyer-Hauschild K, Berndt A and Kosmehl H: Epidermal growth factor receptor kinase domain mutations are rare in salivary gland carcinomas. Br J Cancer 100: 623-625, 2009.

20. Nakano T, Yamamoto H, Hashimoto K, Tamiya S, Shiratsuchi H, Nakashima T, Nishiyama K, Higaki Y, Komune S and Oda Y: HER 2 and EGFR gene copy number alterations are predominant in high-grade salivary mucoepidermoid carcinoma irrespective of MAML2 fusion status. Histopathology 63: 378-392, 2013

21. Warner KA, Adams A, Bernardi L, Nor C, Finkel KA, Zhang Z, McLean SA, Helman J, Wolf GT, Divi V, et al: Characterization of tumorigenic cell lines from the recurrence and lymph node metastasis of a human salivary mucoepidermoid carcinoma. Oral Onco 49: 1059-1066, 2013.

22. Liu X, Ory V, Chapman S, Yuan H, Albanese C, Kallakury B, Timofeeva OA, Nealon C, Dakic A, Simic V, et al: ROCK inhibitor and feeder cells induce the conditional reprogramming of epithelial cells. Am J Pathol 180: 599-607, 2012.

23. Dulbecco R and Vogt M: Plaque formation and isolation of pure lines with poliomyelitis viruses. J Exp Med 99: 167-182, 1954.

24. Noguchi K, Wakai K, Kiyono T, Kawabe M, Yoshikawa K, Hashimoto-Tamaoki T, Kishimoto H and Nakano Y: Molecular analysis of keratocystic odontogenic tumor cell lines derived from sporadic and basal cell nevus syndrome patients. Int J Oncol 51: 1731-1738, 2017.

25. Hiromoto T, Noguchi K, Yamamura M, Zushi Y, Segawa E, Takaoka K, Moridera K, Kishimoto $\mathrm{H}$ and Urade M: Up-regulation of neutrophil gelatinase-associated lipocalin in oral squamous cell carcinoma: Relation to cell differentiation. Oncol Rep 26: 1415-1421, 2011

26. Gupta R, Kalita P, Patil O and Mohanty S: An investigation of folic acid-protein association sites and the effect of this association on folic acid self-assembly. J Mol Model 21: 308, 2015.

27. Rio DC, Ares M Jr, Hannon GJ and Nilsen TW: Purification of RNA using TRIzol (TRI reagent). Cold Spring Harb Protoc 2010 pdb.prot5439, 2010
28. Prophet EB, Mills B, Arrington JB and Sobin LH: Laboratory methods in histotechnology (Armed Forces Institute of Phatology). American Registry of Pathology, Washington, DC, 1992.

29. Seethala RR: An update on grading of salivary gland carcinomas. Head Neck Pathol 3: 69-77, 2009.

30. Ohnishi Y, Minamino Y, Kakudo K and Nozaki M: Resistance of oral squamous cell carcinoma cells to cetuximab is associated with EGFR insensitivity and enhanced stem cell-like potency. Oncol Rep 32: 780-786, 2014.

31. Meng C, Wang S, Wang X, Lv J, Zeng W, Chang R, Li Q and Wang X: Amphiregulin inhibits TNF- $\alpha$-induced alveolar epithelial cell death through EGFR signaling pathway. Biomed Pharmacother 125: 109995, 2020.

32. Telesco SE, Vadigepalli R and Radhakrishnan R: Molecular modeling of ErbB4/HER4 kinase in the context of the HER4 signaling network helps rationalize the effects of clinically identified HER4 somatic mutations on the cell phenotype. Biotechnol J 8: 1452-1464, 2013.

33. Li X, Huang Q, Wang S, Huang Z, Yu F and Lin J: HER4 promotes the growth and metastasis of osteosarcoma via the PI3K/AKT pathway. Acta Biochim Biophys Sin (Shanghai) 52: 345-362, 2020

34. Luna MA: Salivary mucoepidermoid carcinoma: Revisited. Adv Anat Pathol 13: 293-307 2006.

35. Mitra A, Mishra L and Li S: Technologies for deriving primary tumor cells for use in personalized cancer therapy. Trends Biotechnol 31: 347-354, 2013.

36. Okumura Y, Miyabe S, Nakayama T, Fujiyoshi Y, Hattori H, Shimozato K and Inagaki H: Impact of CRTC1/3-MAML2 fusions on histological classification and prognosis of mucoepidermoid carcinoma. Histopathology 59: 90-97, 2011.

37. Tirado Y, Williams MD, Hanna EY, Kaye FJ, Batsakis JG and El-Naggar AK: CRTC1/MAML2 fusion transcript in high grade mucoepidermoid carcinomas of salivary and thyroid glands and Warthin's tumors: Implications for histogenesis and biologic behavior. Genes Chromosomes Cancer 46: 708-715, 2007.

38. Anzick SL, Chen WD, Park Y, Meltzer P, Bell D, El-Naggar AK and Kaye FJ: Unfavorable prognosis of CRTC1-MAML2 positive mucoepidermoid tumors with CDKN2A deletions. Genes Chromosomes Cancer 49: 59-69, 2010.

39. Komiya T, Park Y, Modi S, Coxon AB, Oh H and Kaye FJ: Sustained expression of Mect1-Maml2 is essential for tumor cell growth in salivary gland cancers carrying the $t(11 ; 19)$ translocation. Oncogene 25: 6128-6132, 2006.

40. Wu J, Wang N, Yang Y, Jiang G, Zhan H and Li F: LINC01152 upregulates MAML2 expression to modulate the progression of glioblastoma multiforme via Notch signaling pathway. Cell Death Dis 12: 115, 2021

41. Amelio AL, Fallahi M, Schaub FX, Zhang M, Lawani MB, Alperstein AS, Southern MR, Young BM, Wu L, Zajac-Kaye M, et al: CRTC1/MAML2 gain-of-function interactions with MYC create a gene signature predictive of cancers with CREB-MYC involvement. Proc Natl Acad Sci USA 111: 3260-3268, 2014.

42. Shinomiya H, Ito Y, Kubo M, Yonezawa K, Otsuki N, Iwae S, Inagaki $\mathrm{H}$ and Nibu KI: Expression of amphiregulin in mucoepidermoid carcinoma of the major salivary glands: A molecular and clinicopathological study. Hum Pathol 57: 37-44, 2016.

43. Porcheri C and Mitsiadis TA: Physiology, pathology and regeneration of salivary glands. Cells 8: 976, 2019.

44. Weng PL, Aure MH, Maruyama T and Ovitt CE: Limited regeneration of adult salivary glands after severe injury involves cellular plasticity. Cell Rep 24: 1464-1470.e3, 201

This work is licensed under a Creative Commons Attribution-NonCommercial-NoDerivatives 4.0 International (CC BY-NC-ND 4.0) License. 